\title{
Hybrid Intelligent Control of Coke oven
}

\author{
Gongfa Li Jianyi Kong Guozhang Jiang Jintang Yang Hegen Xiong and Yu hou \\ College of Machinery and Automation, Wuhan University of Science and Technology, Wuhan 430081, Hubei \\ Province, China
}

\begin{abstract}
Aiming at the longitudinal temperature was affected by many reasons, and the control principle of combining the intermittent heating control with the heating gas flow adjustment was adopted. Control strategy and an integrated model of coke oven heating based on hybrid intelligent control methods were built. According to artificial operation and actual condition, fuzzy controller was designed. Intelligent control methods were used to compute the proper amount of stopping heating time and heating gas flow. The application of the system has resulted in energy saving by $2 \sim 4 \%$, coke quality improvement by $3 \sim 5 \%$ and enhanced coke oven life. Obvious economic and social benefinits are obtained.
\end{abstract}

Keywords: Coke oven, Heating intelligent control, Fuzzy control, Neural network

\section{Introduction}

Coke oven is an important raw materials production equipment in such trades as metallurgy industry and chemical industry and so on, produces coke and coal gas mainly, and the quality and output of the products concern the stability of follow-up industrial production directly. Coke oven consumes energy heavenly in the iron and steel enterprise, how to economize energy consumption, and improve quality and output of cokes are key questions of controlling and management of coke oven. It is significant to strengthen the competitiveness and increase economic efficiency of iron and steel enterprise to guarantee coke quality and improve output of coke steadily.

The coke oven was disposed by a lot of cokechambers and flue-chambers alternatively. The coal gas and air enter the coke-chamber to spread and burn after preheating from coke-chamber, then heat produced is spread to coke-chamber by the stove wall. The coal material carries on the high-temperature dry distillation in the coke-chamber, then coke is formed; waste gas produced by burning is discharged after holding retrieving the remaining heat energy via regenerator, flow direction of coal gas, air and waste gas is exchanged per twenty minutes. According to production technology of coke oven, production process of coke oven has the following characteristics: 1) Production process of coke oven belongs to intermittent type, is operated by single stove according to operation planning; 2) Coke oven has characteristics of great inertia and large time-delay ; 3)Mechanism of coking course is complicated, has complexity of nonlinear and coupling parameters; 4)The variable changes violently, results in interfering being strong in the production process; 5)The coke oven is a big hot close system, temperature measurement has particularity and complexity[1].

On the basis of analyzing the existing heating control strategy of coke oven, intelligent control model of coke oven heating is built by making use of linear regression ,neural network and fuzzy control, the control method of combing intermittent heating control with the heating gas flow adjustment is put forward, research on control system of coke oven is carried on. The application of the system in some company indicates that the system can stabilize production of coke oven, reach the anticipated result and has very great practical value.

\section{Control strategy of heating control system in coke oven}

As the control goal of reducing energy consumption , improving coke quality, stabilizing flue temperature, regarding store group, every coke-chamber as control unit, such temperature parameters as final temperature of coke button, temperature on top of regenerator, flue temperature ,coking end temperature are controlled by adjustment coal gas flow, calorific value, air excess coefficient ,heating supplied amount, thus the temperature of heating course in coke oven is optimized and controlled. There are three kinds of control strategies in coke oven heating system, namely feedback control strategy, feedforward control strategy and compound control strategy combined feedback with feedforward [2-4].

\subsection{Feedback control strategy}

The characteristics of feedback control strategy are: According to deviation between real flue temperature, 
real finished carbonization time or real coke temperature and target flue temperature, target finished carbonization time or target coke temperature, considering time-delay factor of coke oven temperature, settlement value of heating gas flow is adjusted in order to realize the optimal heating control of coke oven. Meanwhile, some control systems provide operation guidance of regulating flue-chamber according to judgment of carbonization of cokechamber, wall temperature measurement of cokechamber or coke button temperature and its distribution. Advantages of feedback control are deeper research on coking mechanism isn't need, the mathematics model of accurate course isn't need to set up, the influence of various kinds of parameters is not need to consider, the deviation of controlled parameters is utilized to control. But experience value of an initially heating supplied amount or heating gas flow is confirmed in advance, is changed constantly while implementing. Shortcomings of feedback control are requirement of the real-time characteristic of the course feedback signal strictly ,the disturbance can't be overcame in time, and the time-delay phenomenon is serious, because feedback control just works after disturbance takes place. Exceeding adjustment phenomenon is easy to get. A lot of electric thermocouples are adapted to measure temperature, thus a large amount of expenses of system is caused in this way.

\subsection{Feedforward control strategy}

The characteristics of feedforward control strategy are: Coking heating amount is calculated according to properties of coal and average temperature of coke button, and then coking heating consumption is calculated through thermal balance according to amount of coal charging, production task, heat loss of waste gas and heat dissipation. Finally heating supplied is calculated according to calorific value of gas, air excess coefficient and so on, then gas flow is calculated, and coking heating consumption is adjusted by real temperature of coke button. Advantages of feedforward control are influence of the slow course of temperature when regulation isn't need to consider, influence examined can be dispelled through the feedforward model, great inertia and large time-delay has solved effectively, monitoring points is less, instrument and measure error can be reduced. It is convenient for system to maintain, the result of reducing consumption can be got .Shortcomings of feedforward control are difficulty in calculating coking heating amount accurately, and a lot of variables of calculating coking heating amount are difficult to measure accurately and totally.

\subsection{Compound control strategy combined feedback with feedforward}

Influence produced by unknown and non-examined parameters is dispelled using feedback control. Influence caused by disturbance is compensated by feedforward control and time-delay of feedback is improved in control system combined feedback with feedforward, therefore the coke oven is in the best working state. This kind of control strategy can be divided into two types: one is control strategy with main feedforward and complement feedback, the other is control strategy with main feedback and complement feedforward.

The characteristics of control strategy with main feedforward and complement feedback are: According to planned carbonization time, properties of coal charging, surveying value of temperature in stove wall of coke oven, implementing of production plan .Standard heating supplied amount of coke oven is calculated according to coking heating consumption model as input of gas value calculation model, then for the calculation result of standard heating supplied is revised dynamically according to the surveying value of coal gas calorific value .Finally the best settlement value of the coke oven gas is confirmed.

The characteristics of control strategy with main feedback and complement feedforward are: According to planned carbonization time, properties of coal charging, real carbonization time determined by change law of raw gas, settlement value of flue temperature is calculated by distillation model, then the value is revised dynamically according to surveying value of flue-chamber, finally the best value of gas supplied is confirmed by temperature control model.

\section{Heating intelligent control}

\subsection{Assessment model and method of temperature}

In order to realize automatic control of heating course in coke oven, the measurement value of various control parameters of coke oven should be got firstly, and the most key one is measurement, assessment and prediction of different temperature of coke oven among them.

The key of furnace temperature feedback control is to establish goal flue temperature rationally and accurately, there are a lot of factors influencing goal flue temperature, in order to investigate the influence of various factors and find out quantitative relationship 
between them, it is necessary to carry on research on calculation model of goal flue temperature. But when establishing calculation model of goal flue temperature in fact, generally only several main factors are considered, such as the influence of coal mass, moisture of coal material, carbonization time and operating condition and so on. Analysis model of goal flue temperature is in equation (1).

$F(j)=f(x, y, z, u, v, w, g, k)$

where $F$ is goal flue temperature; $x$ is goal carbonization time; $y$ is goal time; $z$ is passing carbonization time after charging coal; $u$ is real coal mass; $v$ is moisture of coal; $w$ is gas flow; $g$ is prediction temperature of coke button in cokechamber; $j$ is a serial number of coke-chamber; $k$ is revised coefficient.

Assessment and prediction of temperature in coke oven not only consider goal temperature calculation model, but also the interrelation models of various kinds of temperature, such as interrelation model between flue temperature and temperature on top of regenerator, flue temperature and wall temperature of coke-chamber. For example when analyzing the interrelation model between flue temperature and temperature on top of regenerator, temperatures on top of regenerator at machine side and coke side are measured through the electric thermocouple, the average temperature on top of regenerator is changed into longitudinal temperature at machine side and coke side through the interrelation model between flue temperature and temperature on top of regenerator.

This kind of interrelation model is set up generally by adopting linear regression method, but because there is a greater error sometimes in this method, and actual physics system is non-linear system, so neural network is used to build model. When modeling, neural network of three layers is used, neural network structure is $1 \times 6 \times 1$. Input layer is one node among them, average temperature on top of regenerator is inputting value; hidden layer is 6 nodes, nodal function is linear function, flue temperature is output value. Right value and valve value matrix got after neural network learning are used to construct interrelation model between flue temperature and temperature on top of regenerator.

So, on one hand, such information as flue temperature, gas temperature and coke button temperature are obtained according to real-time and historical data, on the other hand, theory calculating value and analyzing value of goal temperature are got using interrelations models of different temperatures, then comparison between theory calculating value and analyzing value is made, thus assessment of optimization of heating temperature in coke oven is made.

\subsection{Intelligent control model of coke oven heating}

At present, iron and steel enterprise usually use "intermittent heating control" control method in heating control system of coke oven, which can well optimize heating control of coke oven in a situation that the heating energy of coke oven is steady and rich [5-7]. But when pressure in main pipe of blast furnace fluctuates violently and heating coal gas flow is insufficient, the method can't instruct attendants how to operate heat controlling, the function of control system can only be analyzed and judged artificially by the attendants, and during stopping heating time, blast furnace gas and coke oven gas stop using at the same time, blast furnace gas is not fully utilized either.

A new control principle combining the intermittent heating control with the heating gas flow adjustment is adopted in control system [8]. It analyses and processes data synthetically such as temperature, flow and calorific value of gas , pushing coke, charging coal, coal mass, water content and planned carbonization time, "stopping heating time" of PLC system and the heating blast furnace gas /coke oven gas flow of DCS system are calculated and established through the model. Therefore heating of coke oven is even and stability, the whole heating level of coke oven is intelligent control, heating intelligent control of coke oven is realized. Its intelligent control model is illustrated in Figure 1.

A compound control system is proposed to control heating of coke oven, which combines feedback control, feedforward control and fuzzy intelligent control. Real-time data of production in coke oven are gathered by the system such as pressure, flow, calorific value and temperature of coal gas, water content, composition of heating gas and dynamic plan and so on, settlement value of controlled parameters is calculated through energy prediction model, namely the feedforward, then the value is transferred to the basic automated system to regulate. According to realtime information such as waste gas temperature, coke button temperature, flue temperature and oxygen content offered by the basic automated system at the same time, the energy balance is feedback regulated according to the fuzzy intelligent control model constantly in the course of heating. Then the settlement value is calculated again in order to enable CI to keep within the range of control, which not only satisfy necessary temperature needed in coking, but also optimal heating control. 


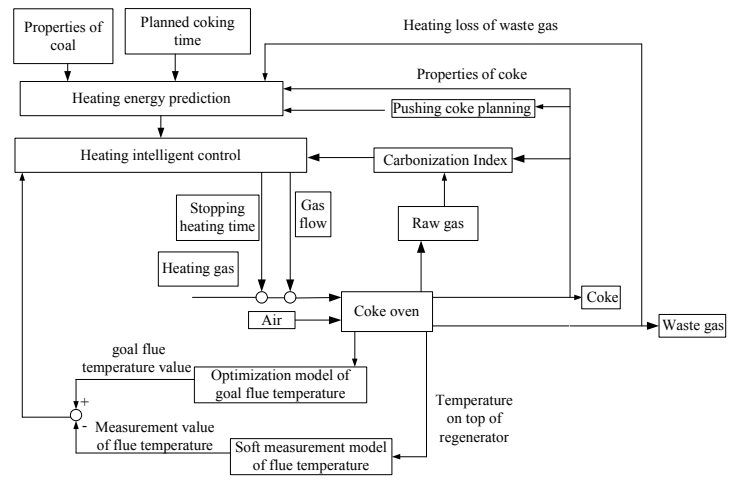

Fig. 1: Intelligent control model of coke oven heating.

\subsubsection{Feedforward control model}

If the total coking heating amount, heating dissipation of coke oven body and sensible heating of exhaust gas are known, then the total output heating amount is got. Therefore feedforward gas flow $V_{0}$ is calculated according to the thermal balance equation. Among them the calculation of every parameter is as follows [1].

If the total coking heating amount, heating dissipation of coke oven body and sensible heating of exhaust gas are known, then the total output heating amount is got. Therefore feedforward gas flow $V_{0}$ is calculated according to the thermal balance equation. Among them the calculation of every parameter is as follows [1].

1) Burning heat $Q_{1}$ $Q_{1}=V_{0} \times(1-m \tau) \times Q_{\text {net }}$

Where $m$ is exchange times of coke oven per hour; $\tau$ is exchange time; $Q_{\text {net }}$ is calorific value of coal gas.

2) Sensible heating $Q_{2}$ of coal gas

$$
Q_{2}=V_{0} \times(1-m \tau) \times T_{m} \times C_{m}
$$

Where $T_{m}$ is temperature of coal gas entering coke oven; $C_{m}$ is specific heat of coal gas.

3) Sensible heating $Q_{3}$ of air

$$
Q_{3}=V_{0} \times(1-m \tau) \times \alpha \times T_{k} \times\left(C_{k}+\psi_{s} \times W_{s} \times C_{s}\right)
$$

Where $\alpha$ is ideal air fuel ratio; $T_{k}$ is air temperature; $C_{k}$ is specific heat of air; $\psi_{s}$ is the relative humidity; $W_{s}$ is the content of the saturation moisture in the air; $C_{s}$ is specific heat of water-gas in the air.

4) Sensible heating $Q_{4}$ of coal entering coke oven

$$
Q_{4}=G_{m} \times C_{m} \times T_{m}
$$

Where $G_{m}$ is mass of coal entering coke oven; $C_{m}$ is specific heat of coal entering coke oven; $T_{m}$ is temperature of coal entering coke oven.

Total input heating amount is got according to above calculation.

$$
Q_{\text {input }}=Q_{\text {oupput }}=Q_{1}+Q_{2}+Q_{3}+Q_{4}
$$

3.2.2. CI (carbonization index) feedback model

$\mathrm{CI}$ index is used to revise coking heating consumption.
CI used in model of the control system is calculated according to the following equation.

$$
C I=t_{\text {coking }} / t_{\text {Tmax }}
$$

Where $t_{T \max }$ is the time from coal charging in coke-chamber to when the temperature of the waste gas passes the peak; $t_{\text {coking }}$ is the time of finished carbonization of each coke-chamber.

Prediction model of $t_{\text {coking }}$ is shown as following.

$t_{\text {coking }}=A \times t_{\text {Tmax }}+C$

Where $t_{T \max }$ is the time from coal charging in coke-chamber to when the temperature of the waste gas passes the peak; $A$ and $C$ are characteristic coefficient of coke oven.

$\mathrm{CI}$ is a carbonization parameter to control coking production management, and it fluctuates among 1.21.25 suitably. Goal flue temperature is revised according to CI.Their relationships are shown as Table1.

\begin{tabular}{|c|c|}
\hline $\mathrm{CI}$ & Revised value of temperature \\
\hline $\mathrm{CI}>1.35$ & $-3^{\circ} \mathrm{C}$ \\
\hline $1.30<\mathrm{CI} \leq 1.35$ & $-2^{\circ} \mathrm{C}$ \\
\hline $1.25<\mathrm{CI} \leq 1.30$ & $-1^{\circ} \mathrm{C}$ \\
\hline $1.20<\mathrm{CI} \leq 1.25$ & $0^{\circ} \mathrm{C}$ \\
\hline $1.15<\mathrm{CI} \leq 1.20$ & $1{ }^{\circ} \mathrm{C}$ \\
\hline $1.10<\mathrm{CI} \leq 1.15$ & $2{ }^{\circ} \mathrm{C}$ \\
\hline $\mathrm{CI}<1.10$ & $3^{\circ} \mathrm{C}$ \\
\hline
\end{tabular}

Table1: Revised relationship between CI and goal flue temperature.

\subsubsection{Temperature feedback model}

Goal flue temperature of coke oven is the goal value of average temperature at machine side and coke side, is a main craft index to guarantee coke button ripe within carbonization time. There are a lot of main factors influencing goal flue temperature such as carbonization time, temperature in the center of coke button, piling density of coal, water content, width of coke-chamber, thickness of stove wall .Because there are many variables and restrains, suitable optimization method is necessary to adopt. Through analyzing some main factors influencing goal flue temperature and course of conducting heating of coke oven, conducting heating model is set up, thus the relationship between carbonization time and width of coke-chamber, thickness of stove wall, thermal conductance rate of coal material and stove wall, thermal diffusion rate of coal material, flue temperature, temperature in the center of coke button. Finally the optimal model of goal flue temperature is built.

According to the production technology of coke oven, there is very strong correlation between temperature on top of regenerator and flue temperature of coke oven, this kind of correlation can be expressed through LR (linear regression) model. Electric 
thermocouples are installed on top of twenty typical regenerators at machine side and coke side respectively, and the exchange signal of the exchanger is inputted into DCS system. After exchanging ten minutes and twenty minutes, when the temperature is stable in regenerator, temperature of regenerator discharging waste gas is measured, average temperature of two times is got, predicted value $y_{1}$ is got according to LR model.

The basic linear relationship between flue temperature and temperature on top of regenerator can be described with the LR model. However, because of the complexity of coke oven production process, there are nonlinear relationship between them according to analyzing the sample data obtained from the production process, the model is built using neural network. According to the neural network model, predicted value $y_{2}$ of flue temperature is got. After receiving present value $y_{1}$ and $y_{2}$, output $T(k)$ of flue temperature soft measurement model is got after weighing combination of two values.

$$
\hat{T}(k)=\alpha \hat{Y}(k)+\beta \hat{Y}_{2}(k)
$$

Where $\alpha+\beta=1$, and $\mathrm{O} \leq \alpha, \beta \geq 1$.Initial value of $\alpha$ and $\beta$ is equal, and they are changed by rules as following, $y(k-1)$ is real value of flue temperature at early moment .

RULE1: IF abs $\left(\hat{y_{2}}(k-1)-y(k-1)\right) \leq 1{ }^{\circ} \mathrm{C}$, THEN $\beta(k)=1, \alpha(k)=0$;

RULE2: IF abs $\left(\hat{y_{2}}(k-1)-y(k-1)\right)$ is minimum, THEN $\beta(k)=1.5 \beta(k-1)$;

RULE3: IF abs $\left(\hat{y_{2}}(k-1)-y(k-1)\right)$ is maximum, THEN $\beta(k)=0.5 \beta(k-1)$.

Goal flue temperature value is got by optimization model of goal flue temperature, and measurement value of flue temperature is got by flue temperature soft measurement model according to temperature on top of regenerator.

\section{Fuzzy control model}

\subsection{Analysis of fuzzy control model}

Fuzzy control is the simulation behavior of artificial intelligence, utilizes the fuzzy theory to set up some rules of control, controls the production process to reach the satisfactory control result. The basic thinking of fuzzy control model in the system is according to deviation between present gas flow and feedforward gas flow, deviation between standard flue temperature and real flue temperature, and a temperature variation tendency of real flue temperature, final gas flow is adjusted through certain fuzzy control algorithms.

$\Delta V=$ present gas flow- feedforward gas flow (10)

$\Delta T=$ standard flue temperature- real flue temperature

$\Delta C=$ flue temperature at present- flue temperature at last moment

Where $\Delta V, \Delta T$ and $\Delta C$ all include three kinds of value, namely greater than zero, equal zero, smaller than zero approximately.

The control algorithm of final gas flow adopts the fuzzy control method, $\Delta V, \Delta T$ and $\Delta C$ are as the input of the fuzzy controller, the change amount $\Delta U$ of gas flow is got through fuzzy control algorithm.

\subsection{Design of fuzzy controller}

Deviation between measuring value and settlement value will be divided into 3 grades[9] [10], namely negative, normal and positive respectively, then every input parameter has 3 kinds of situation, therefore these parameters make up as 27 kinds of situation. According to the actual conditions, each kind of situation is adopted corresponding operation, and opening degree of the gas valve will increase or reduce. 27 rules are shown as table2 where NG represents " negative ", NM represents " normal ", PS represents " positive", IC represents " increasing ", DC represents " decreasing ", KEEP represents " keeping ".

Various kinds of influence and variation tendency of gas flow are summed up into 27 rules synthetically in the model according to artificial operation experience, fuzzy control model of gas flow has set up, and thus heating intelligent control of coke oven is realized.

\begin{tabular}{|c|c|c|c|c|}
\hline Rule number & $\Delta V$ & $\Delta T$ & $\Delta C$ & $\Delta U$ \\
\hline 1 & NG & NG & NG & IC $10 \%$ \\
\hline 2 & NG & NG & NM & IC $10 \%$ \\
\hline 3 & NG & NG & PS & IC 5\% \\
\hline 4 & NG & NM & NG & IC 5\% \\
\hline 5 & NG & NM & NM & IC 5 $\%$ \\
\hline 6 & NG & NM & PS & KEEP \\
\hline 7 & NG & PS & NG & KEEP \\
\hline 8 & NG & PS & NM & DC 2 $\%$ \\
\hline 9 & NG & PS & PS & DC $2 \%$ \\
\hline 10 & NM & NG & NG & IC 5 $\%$ \\
\hline 11 & NM & NG & NM & IC 2 $\%$ \\
\hline 12 & NM & NG & PS & KEEP \\
\hline 13 & NM & NM & NG & IC 2 $\%$ \\
\hline
\end{tabular}




\begin{tabular}{|c|c|c|c|c|}
\hline 14 & NM & NM & NM & KEEP \\
\hline 15 & NM & NM & PS & DC $2 \%$ \\
\hline 16 & NM & PS & NG & KEEP \\
\hline 17 & NM & PS & NM & DC $2 \%$ \\
\hline 18 & NM & PS & PS & DC $5 \%$ \\
\hline 19 & PS & NG & NG & IC $5 \%$ \\
\hline 20 & PS & NG & NM & IC $2 \%$ \\
\hline 21 & PS & NG & PS & KEEP \\
\hline 22 & PS & NM & NG & KEEP \\
\hline 23 & PS & NM & NM & DC $2 \%$ \\
\hline 24 & PS & NM & PS & DC $2 \%$ \\
\hline 25 & PS & PS & NG & DC $2 \%$ \\
\hline 26 & PS & PS & NM & DC $5 \%$ \\
\hline 27 & PS & PS & PS & DC $10 \%$ \\
\hline
\end{tabular}

Table2: Control rule of fuzzy intelligent controller.

\section{Realization of heating intelligent control of coke oven}

Therefore the heating intelligent control is achieved as following.

1) Considering properties of coal and coke, planned coking time and pushing coke planning, the $Q_{\text {input }}$ is got according to heating energy prediction model. Then the feedforward gas flow $V_{0}$ is calculated according to formula (2) - (6)

2) CI is calculated according to formula (7) - (8), therefore the revised goal flue temperature is got.

3) $T(k)$ is got by formula (9).

4) Deviations between goal value and measurement value are calculated by formula (10) (12) to revise the gas flow $V_{0}$.

When operation condition of production changes, the change range of temperature will often exceed ($6,+6)$, if the simple control method is still adopted , because of the great inertia of coke oven, big exceeding adjusting amount and too long adjustment time are caused. Aiming at above-mentioned situations, a prediction part in the controlling course has been increased (shown as Fig.2). Furthermore the deviation of temperature is judged firstly, when the range of deviation does not exceed $(-6,+6)$, fuzzy control is adopted. If it exceeds above-mentioned ranges, BangBang intelligent control is used. So coal gas flow and stopping heating time are adjusted, control precision and fast response of controlled target are guaranteed.

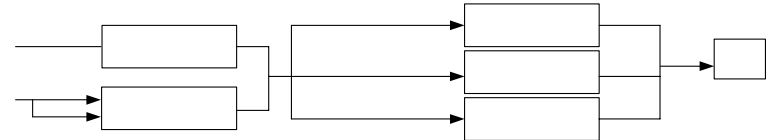

Fig. 2: Intelligent control.

\section{Practical running result and conclusions}

This system has already been succeeded in applying intelligent control system of coke oven heating in some iron and steel company. Settled temperatures of machine side and coke side are $1260^{\circ} \mathrm{C}$ and $1310^{\circ} \mathrm{C}$ respectively in coke oven production, temperature control of machine side and coke side are shown just as Fig. 3 and Fig. 4 respectively. The statistics show that temperature errors of machine side and coke side are up to $89.5 \%$ and $86.7 \%$ among $\pm 5^{\circ} \mathrm{C}$, meet the real industrial production demand.

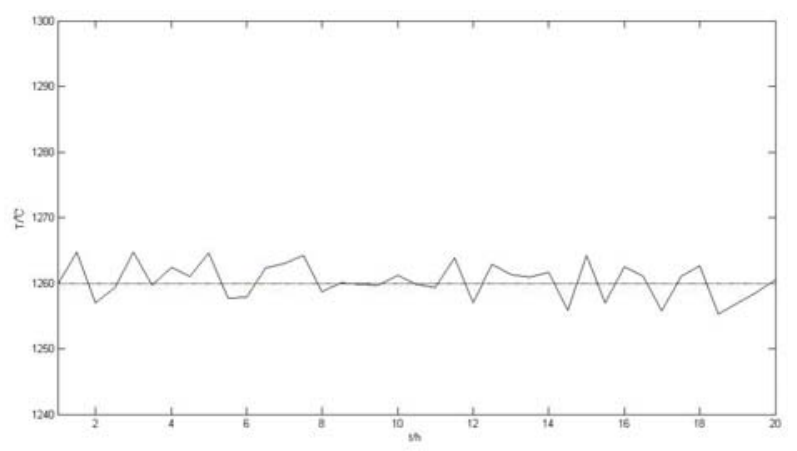

Fig.3: Temperature control of machine side.

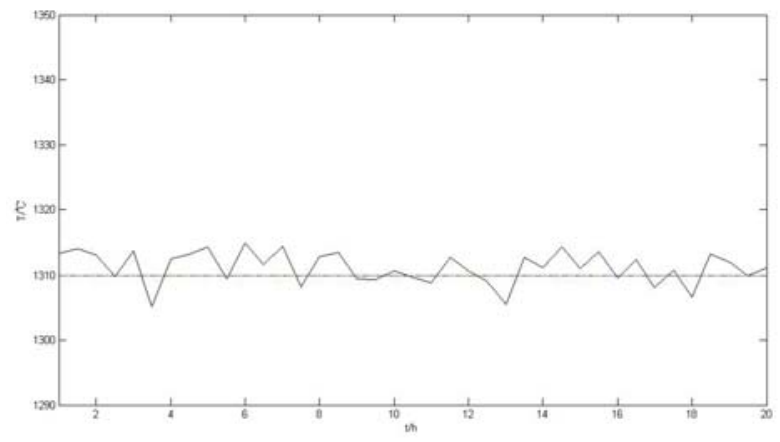

Fig.4: Temperature control of coke side.

The system is put into operation in the company for more than one year, the system runs normally, the result is good. It's easy to operate and master for operators, lightens labor intensity, and has improved operation condition. The system not only can regulate the heating supplied amount of coke oven in time, but 
also have stronger anti-interference ability. The system has reduced fluctuation of whole temperature of coke oven to a great extent, and heating supplied amount needed is also reduced relatively, so consumption of blast furnace gas has been reduced. At the same time stable coefficient is improved too, therefore the life of coke oven is lengthened and coke quality is improved. It can achieve heating intelligent control of coke oven and has very great practical value.

\section{Acknowledgment}

This work is partially supported by the Science and Technique Foundation of Hubei Province in China for the supporting (Grant No.20063002066).

\section{References}

[1] W.F. Yan and M.D Zheng, Heating regulation and energy-conservation of coke oven, Hefei Polytechnic University Press, 2005.

[2] J. Swanijung and P. Palmu, Development of Coke-oven Battery Process Management System at Rautaruukki Steelworks. International Journal of Iron and Steel Engineer, 1: 46-49, 2001.

[3] J.Swanijung and P. Palmu, Experience and results of new heating control system of coke oven batteries at Rautaruukki OY Raahe Steel, Ironmaking Conference Proceedings, pp.79-83, 1997.

[4] E. T. Battel and K. L. Chen, Automatic coke oven heating control system at Burn Harbor Works for normal and repair operation, Ironmaking Conference Proceedings, pp. 499-504, 1997.

[5] Z.C. Zou,Heating control system of coke oven for the 3rd phase of Baosteel. Chinese Journal of Metallurgical Industry Automation, 5: 1619,1999.

[6] Y.W Chen ,Heating control using feedforward and feedback control principle for No 3 coke oven battery of Jiuquan Iron \& Steel Co.Chinese Journal of Metallurgical Industry Automation, 3: 16-19,1999.

[7] J.W. Gao, Y.D. Ye, T.Y Shi, Q.H. Jiang and L. Jia,Research and Application on Coke Oven Heating Intelligent Control System.Chinese Journal of Information and Control, 1: 86-91, 2003.

[8] G.Z Jiang, J.Y. Kong, G.F. Li , B.Huang and J.L. Nan, Intelligent Control System for Coke Oven Heating.Chinese Journal of Iron and Steel , 11 73-76, 2006.
[9] E. Kim.,A new approach to numerical stability analysis of fuzzy control systems.IEEE Trans on Systems, 1: 107-113, 2001.

[10] H .Tanaka, M.Yasuno and H.OSHIMA, Application of Fuzzy Inference to Combustion Control for Coke Oven,Ironmaking Conference Proceedings, pp.509-513,1992. 